\title{
Hidden Harvest's transformative potential: An example of 'community economy'
}

\author{
Patricia Ballamingie, ${ }^{\text {* }}$ Chloé Poitevin-DesRivières, ${ }^{\mathrm{b}}$ \\ and Irena Knezevic ${ }^{c}$ \\ Carleton University
}

Submitted December 10, 2018 / Revised February 18 and March 29, 2019 / Accepted March 30, 2019 /

Published online July 30, 2019

Citation: Ballamingie, P., Poitevin-DesRivières, C., \& Knezevic, I. (2019). Hidden Harvest's transformative potential: An example of 'community economy.' Journal of Agriculture, Food Systems, and Community

Development, 9(Suppl. 1), 125-139. https://doi.org/10.5304/jafscd.2019.091.036

Copyright (C 2019 by the Authors. Published by the Lyson Center for Civic Agriculture and Food Systems. Open access under CC-BY license.

\begin{abstract}
Drawing on an in-depth case study of Hidden Harvest Ottawa - a for-profit social enterprise that aims to legitimize and support the practice of harvesting fruits and nuts in urban areas - this article explores the transformative potential (both realized and unrealized) of place-based urban foraging. It briefly delineates the organizational model employed, including its innovative practices and strategic 5-year vision. It then explores Hidden Harvest's transformative potential realized: notably, it reconceptualizes surplus (and thus profit); makes visible a nonmonetary social return on investment

a $*$ Corresponding author: Patricia Ballamingie, Associate Professor, Geography \& Environmental Studies, Carleton University; Loeb B349, 1125 Colonel By Drive; Ottawa, ON K1S 5B6 Canada; patricia.ballamingie@,carleton.ca

b Chloé Poitevin-DesRivières, Ph.D. Candidate (ABD), Geography \& Environmental Studies, Carleton University; chloe.poitevin@,carleton.ca

c Irena Knezevic, Associate Professor, Communication Studies, Carleton University; irena.knezevic@,carleton.ca
\end{abstract}

(SROI, defined as substantive contributions to building community, adaptive capacity, prosperity, social capital, and community-based food security); normalizes access to public space for food provisioning; and, finally, frames Hidden Harvest as an illustrative example of Gibson-Graham's (2006) notions of community/alternative/ethical economy, an initiative that destabilizes dominant economic assumptions while fostering meaningful interconnection. Throughout this article, we argue that only through collective resignification of our economy can initiatives such as Hidden Harvest adequately receive the support warranted by its impact and outcomes to fully realize its potential and achieve long-term viability.

\footnotetext{
Funding Disclosure

This research emerged from the Nourishing Communities: Sustainable Local Food Systems Research Group, led by Alison Blay-Palmer at Wilfrid Laurier University. This case study is one of many in The Social Economy of Food, an Insight grant project funded by the Social Sciences and Humanities Research Council of Canada.
} 


\section{Keywords}

Social Enterprise, Urban Foraging, Gleaning, Community Economy, Social Return on Investment, Fruit Rescue

\section{Introduction}

Gleaning, a term historically associated with the harvest of surplus or economically nonviable produce from farmland, has been extended over the past two-and-a-half decades to include the collection of fruit and nuts in urban areas, sometimes also described as fruit "rescue." Food rescue organizations can be found throughout North America, and are largely citizen-based and volunteer-driven. In fact, the movement has become global through Falling Fruit, a massive collaborative initiative to map urban harvests around the world (Falling Fruit, 2018). In Canada, volunteer-led urban harvesting initiatives have emerged in many major cities: for example, LifeCycles, in Victoria (1994); Not Far From the Tree, in Toronto (2008); Operation Fruit Rescue, in Edmonton (2009); and Les Fruits Défendus, in Montreal (2011/2). In 2012, Hidden Harvest Ottawa (referred to throughout as Hidden Harvest), a for-profit social enterprise, emerged in Ottawa to legitimize and support the practice of harvesting fruits and nuts in urban areas. Hidden Harvest attempts to address food security issues in a way that makes use of locally available resources: the large amount of unused and wasted fruits and nuts on trees throughout the city.

The motivations of these organizations are partially material, in that they deal directly with food in its physical form. However, the larger driving forces for groups like Hidden Harvest include social dimensions such as building community, environmental considerations such as diverting waste, and the desire to contribute to systemic change. For instance, in seeking to collect and use previously wasted food, and ultimately to alter the definition of urban fruits as food rather than waste products, Hidden Harvest works to create a more resilient local food system and economy. It is these organizational characteristics, rather than just
Hidden Harvest's self-declared status as a social enterprise, that situate its efforts within the social economy of food.

Social economy is an umbrella term that refers to collective economic activities for which economic benefits are only one of, and often not the primary, set of motives. Rather than a set of discrete organizations, the social economy is an organizing principle that encompasses a wide range of activities and values (McMurtry, 2008) that put people before profits. Such initiatives are community-oriented, autonomously managed, and participatory (Canadian CED Network, n.d.), and include such enterprises as cooperatives, credit unions, and even notfor-profit organizations. Social economy is sometimes also referred to as the 'collective economy' or 'third sector,' as distinguishable from the government and private sectors. Because of the sector's emphasis on social, and to a lesser extent environmental, values alongside its recognition of the importance of economic viability, the social economy sector stands in contrast to the core values of the neoliberal economic order. The neoliberal order prioritizes free market, privatization, and deregulation (Harvey, 2007) and privileges individual economic gain at the expense of collective social and environmental benefits. The resulting social inequity and environmental degradation (Milanovic, 2016; Perelman, 2003) have been particularly salient in the food system (International Panel of Experts on Sustainable Food Systems [IPES-Food], 2016; Patel, 2007). Social economy initiatives seek to address some of those concerns, by trading profit maximization for the pursuit of multiple collective goals.

Whereas social economy has been studied substantially and is even enshrined in some countries' legislative frameworks, 1 the sector has focused largely on cooperatives, which have a long and rich history around the globe (Thompson, 2012). More recently, parts of the financial sector have begun to turn to "impact investing," an investment approach that conceptualizes social and environmental values as add-ons to traditional investing (Responsible Investment Association, 2016). Smaller, less

\footnotetext{
${ }^{1}$ Belgium, Spain, Greece, Portugal, France, and Romania have all passed laws in recent years to protect social economy and recognize its contributions to social prosperity (European Economic and Social Committee, 2017).
} 
formally organized initiatives receive less attention in the literature on social economy, although our anecdotal knowledge suggests they may be more numerous and more diverse than enterprises like cooperatives.

Our study of Hidden Harvest aims to address that gap and consider how these understudied forms of social economy destabilize dominant economic assumptions and foster meaningful interconnection by redefining such concepts as surplus, return on investment, and public space. In doing so, we highlight the work of food systems activists, such as the proponents of Hidden Harvest, to explore the transformative potential of place-based urban foraging. Specifically, we draw on GibsonGraham's (2006) notions of 'community economy' to suggest that urban foraging helps resignify our economy, and as such warrants community and public support.

\section{Legitimizing, Conceptualizing, and Critiquing Urban Gleaning}

Contemporary foraging is growing in popularity, "transcends the urban-rural divide," and is practiced by diverse populations (Sachdeva, Emery \& Hurley, 2018, p. 978). Within this larger set of activities, urban gleaning has received particular scholarly attention as it proves to be more accessible (and more visible) than foraging in rural forested areas. Scholars of urban gleaning have sought to legitimize, normalize and laud the practice; conceptualize its significance; and offer critical perspectives, in part by delineating its associated challenges.

Poe, McLain, Emery \& Hurley (2013) have sought to legitimize the practice of foraging and gathering from urban lands. They emphasize the need to reduce regulatory barriers to facilitate such activity, noting uneven governance regarding collection of food on public lands, and differing public and municipal government attitudes (McLain, Hurley, Emery \& Poe, 2014). In this regard, city planners and landscape ecologists have begun to recognize the myriad benefits of urban forests, including ecosystem services, although improved food security remains an underrecognized advantage (Clark \& Nicholas, 2013). The authors further identify proximity to people and the high level of engagement in urban agriculture initiatives as contributing factors. However, they warn that despite the growing popularity and interest in urban harvesting projects, the scalability of these initiatives is difficult to ascertain (Clark \& Nicholas, 2013). Cognizant of its popularity, Marshman (2015) explores the myriad motivations people have to pursue urban gleaning across five case study sites in Ontario, identifying three key reasons (to mitigate food waste, build community, and access free food) amid other desires (to engage socially or generally seek alternatives).

Clark and Nicholas (2013) argue that urban harvesting requires a more fulsome theorization. To this end, McLain et al. (2014) offer a way to conceptualize the significance of urban harvesting. The authors generate insights from four U.S. cities (Baltimore, New York, Philadelphia, and Seattle) to frame foraging for "wild" foods in urban settings as a subversive practice that can reconceptualize human agency in urban green spaces while supporting sustainability goals, and that understands urban green spaces as providers of ecological services and material products. The authors write, "The spaces in which foraging occurs, like those dedicated to urban agriculture, constitute landscapes of material production in the city and are important for more than just their aesthetic, recreational, and ecological values" (McLain et al., 2014, p. 236). Urban foraging - what McLain et al. characterize as a "productive nature practice" (2014, p. 237) - connects people to nature through urban ecologies, green spaces, and edible landscapes. They note in particular the potential for planners of urban green space to broaden the distribution of benefits in their consideration of and support for foraging in order to be more inclusive and environmentally just (McLain et al., 2014). McLain et al. (2014) further note that urban foraging or harvesting is a distinctly noncapitalist practice, as outlined by Gibson-Graham (2006), since predominantly nonmarket values are derived from collected products. This is a notion we explore more fully in this article.

Urban gleaning projects offer a means to provide fresh and healthful foods to low-income populations, often through partnerships with emergency food organizations, such as food banks. 
However, the reliance on emergency food organizations in Canadian cities remains a concern in and of itself, as these do little to attend to the systemic issues that drive unequal access to healthy foods (Wakefield, Fleming, Klassen, \& Skinner, 2012). Wakefield et al. (2012) note that, while gleaning projects can help to address the lack of nutritious foods offered by emergency food providers, concerns with regards to the stigma associated with food bank usage persist. Although emergency food organizations provide necessary services, they entrench feelings of marginalization and powerlessness in those who are food insecure (Knezevic, Hunter, Watt, Williams, \& Anderson, 2014).

In building legitimacy around urban gleaning and harvesting, relationships between people and urban natures must be examined. Often, people are hesitant to collect wild foods, ${ }^{2}$ which are viewed as forbidden, particularly in public spaces. McLain et al. (2014) surmise that the relationship between people and urban nature remains predominantly oriented toward conservation, rather than use. They allude to the "museumification" of nature in parks, which acknowledges the benefits trees provide to the broader ecosystem, but not to people as goods to be harvested (McLain et al., 2014). This notion of nature as something to be observed and untouched by people, upheld by practices such as "Leave No Trace" outdoor recreation and regulations in many public parks, may feed into this idea that harvesting food from trees on public lands is inherently "wrong." Although fruit- and nutbearing trees are often planted throughout cities, their potential use value as food is neglected, as foraging is not included in land-use planning considerations (McLain et al., 2014). Proponents of urban gleaning seek to broaden the conceptualization of urban agriculture to include edible landscapes and both formal and informal foraging.

Finally, Bartlett (2012), Poe et al. (2013), and Nordahl (2014) have sought to problematize urban gleaning and delineate its associated challenges. Poe et al. (2013) and Nordahl (2014) note that urban areas are potentially contaminated and thus pose food safety concerns. Specific sources of contamination might include heavy metal and chemical contamination from former brownfield sites, feces from urban pets, and salt runoff from roadways (Nordahl, 2014). Bartlett (2012) identified the health hazard of rotting, surplus fruit that falls to the ground if unharvested, and the corresponding need to dispose of it-a problem that may be exacerbated if municipalities begin to increase their plantings of edible landscapes. Certainly, proponents must remain attentive to the laws governing urban harvest and keep food safety and other legislative barriers in mind at all times. Some question whether online mapping software, such as Google Maps, can identify edible resources accurately, and they are concerned further with the ability for people to tamper with or delete data. In addition, some critics view the model of urban harvesting as an inefficient and illegitimate means of producing food and assuring food security in cities that has little to no potential for scalability. In fact, scaling up and out ${ }^{3}$-becoming bigger and more profitable-brings potential liability, exposure, regulation, competition, and criticism.

Of note to our study are the dimensions of urban gleaning that place it squarely in the social economy sector. The materiality of gleaning makes it an economic activity, but one where the neoliberal notions of economy are set aside to give way to the social and environmental benefits that gleaning offers to the communities in which it takes place.

\section{Applied Research Methods}

This research reflects one of several case studies explored through a Canadian research project called The Social Economy of Food: Informal, under-recognized contributions to community prosperity and resilience. The project conducted 12 case studies through a set of common research questions that took a participatory approach, in which community groups under study took active

\footnotetext{
${ }^{2}$ Note that foraged foods, wild foods, and country foods are used interchangeably in literature and policy alike; e.g., Indigenous communities in Canada prefer "country foods."

${ }^{3}$ Hidden Harvest's "scaling up and out" proved localized to Ottawa, as increasing numbers of trees were mapped, the number of volunteer neighborhood leaders grew, and the software infrastructure allowed for autonomous organization.
} 
roles in shaping and conducting the research. The case studies allowed for comparative analysis across sites and also addressed a variety of practices, from a community investment fund in the province of Nova Scotia, to an endeavor to reestablish wild rice in an Ontario lake, as a form of cultural and environmental remediation. The cases examined understudied activities within the social economy that bolster food security and community development while aiming to benefit marginalized communities.

Research assistant and co-author PoitevinDesRivières compiled an in-depth case study of Hidden Harvest Ottawa over the course of a year, capturing the various activities and outputs of the organization (see Poitevin-DesRivières, 2018a, 2018b). Specifically, Poitevin-DesRivières conducted semistructured interviews with Hidden Harvest co-founders and was able to derive insights through participant observation of harvest events, workshops, and lobbying activities. With regard to the latter, she attended council meetings at city hall to offer support for the organization based on her findings, which was part of our action research agenda. Through participant observation, we placed harvest activities in particular geographies, lending a practical and material understanding of harvest events. The physical aspects of research sites, along with the people present and their interactions, can generate useful research materials (Elwood \& Martin, 2000). This deliberate immersion through participant observation allowed for an understanding of context-specific dynamics and practices to "produce rich, detailed and empathic understandings" of particular social and cultural groups (Anderson, 2004, p. 255).

The study is only partly about Hidden Harvest, and is more substantially about utilizing the organization as a site through which to generate insights and practices related to the social economy. In other words, this paper is less about evaluating Hidden Harvest and more about the lessons this organization offers to scholarly efforts to better understand the social economy. The participatory, community-based approach in this work facilitated this understanding and allowed for key insights to develop collaboratively between community and academic researchers. Consequently, the paper may at times seem uncritical of Hidden Harvest. However, in this process, Hidden Harvest is not the primary subject of study. Instead, the organization acts as a vehicle that helps identify and articulate the reasons for, and pathways to, effective resignification of economic activities.

\section{Hidden Harvest: Rescuing Urban Fruit and Nuts}

Jason Garlough and Katrina Siks, cofounders of Hidden Harvest Ottawa, frame their work as "rescuing" urban fruit and nuts that would otherwise go to waste, and "sharing it with those in need" (Hidden Harvest, n.d. -a). Bethea (2018) aptly describes them as the "Robin Hoods of food waste." Poitevin-DesRivières (2018a, 2018b) has explored their history and innovative model at length, and thus it will only be summarized here. Specifically, this section will briefly delineate the organizational model employed and highlight its various substantive contributions to building community, adaptive capacity, prosperity, social capital, and community food security, all of which are aspects of sustainable human economies.

In spring 2011, a group of like-minded people met and became friends through an Edible Wilds course run by prominent and much-loved Ottawa field naturalist, interpreter and educator Martha Webber. During a harvest weekend later that year, the group planted the seed of the idea that became Hidden Harvest. In 2012, the city of Ottawa released data that revealed the existence of more than 4,000 unharvested food-bearing trees on city property, ${ }^{4}$ spurring Garlough and Siks into action. In August 2012, they launched Hidden Harvest in an effort to mitigate local food waste and put it to good use. Using that city data as a starting point, Hidden Harvest has mapped diverse fruit and nut trees on public, and some private, properties across the city. Groups of volunteers participate in insured harvest events, organized by "neighborhood leaders" trained by Hidden

\footnotetext{
${ }^{4}$ In 2013, the city hired consultants to understand the impact of the invasive and destructive emerald ash borer (Agrilus planipennis), which indirectly facilitated the identification of 17,000 food-bearing trees.
} 
Harvest. The bounty is then split: one-quarter goes to the nearest food agency (shelter or food bank), and the remaining three-quarters is divided equally among the homeowner (if private property), the volunteer harvesters, and Hidden Harvest, who raise funds for the initiative by selling their share to local restaurants and processors.

Run as a for-profit enterprise, Hidden Harvest "is a social purpose business aiming to create a blended return on investment that is financial, social and environmental" (Hidden Harvest, n.d.a, "The Model," para. 1). However, the initiative is run on a self-described "shoe-string budget," without full-time staff, an office, or a phone number (Hidden Harvest, n.d.-a, "The Model," para. 2). It manages to achieve a disproportionate impact in terms of its desired triple return based on volunteer efforts and tremendously dedicated leaders, who bring creativity, innovation, and technological skills to virtually everything they do. As such, they provide a textbook example of a social enterprise, employing "entrepreneurial methods, such as risk-taking, innovation, and team building, to bring about positive social change, typically with extremely scarce resources" (Johnson \& Ballamingie, 2010, p. 1). Operating within the social economy - straddling private and public sectors-Hidden Harvest is more akin to a notfor-profit or charitable organization than a forprofit enterprise, in spite of its earnest efforts to become economically viable. As Garlough laments: "A good deal of the success of the Hidden Harvest model is the charitable aspect. Nobody gets paid anything, unless we get grants" (Garlough, 2018).

For the past six years, Hidden Harvest has sought to become economically viable and selfsustaining through entrepreneurial activities, strategic partnerships, and efforts aimed at raising the organization's profile. First, it partnered with Oak Computing to develop its website to allow the public to register trees for harvest and sign up to volunteer. Garlough, who possesses advanced technical skills, further developed an interactive map of potential harvests and an email notification system for upcoming harvests. In 2012, it shared its first compelling story digitally. It now has a total of seven clips posted on Vimeo (Hidden Harvest, n.d.-b). In 2012, it also sought to raise funds by selling food-bearing trees, a venture, according to Garlough, "that broke even but did not generate sufficient profit to also support core organizational operating costs" (Garlough, 2018). In 2013, it filmed a humorous My Giving Moment for Governor General David Johnston, titled Hinterland Who's Who: Urban Harvesters (Hidden Harvest, 2013a). From 2014 to 2015, it partnered with Bridgehead Coffeehouse to receive CA $\$ 1$ to $\mathrm{CA} \$ 2$ for every pound of sales on a fundraiser Hidden Harvest Blend coffee, and with Beau's All Natural Brewing Company to raise funds by running the midway games at their annual Oktoberfest event. Throughout its existence, Hidden Harvest remained politically active in an attempt to create regulatory legitimacy for urban fruit tree harvesting in Ottawa, including the food value of trees. Its ongoing advocacy for Ottawa urban forests resulted in Hidden Harvest being featured in Ottawa's Urban Forest Management Plan and influencing recommendations \#17 (develop an urban tree product utilization strategy [2022-2025]) and \#23 (draft an urban forest outreach and engagement strategy (2018-2021]) (City of Ottawa, 2017). In 2018, the organization was named Best Social Enterprise at the 2nd Ottawa Impact Awards for its work to make Ottawa "a more inclusive, safe, resilient and sustainable city” (Monro, 2018, para. 2).

Hidden Harvest's steering committee (board members with whimsical roles such as income eagle, strategic policy porcupine, secretariat hare, tech fox, governance groundhog, cataloguing chipmunk, and outreach racoon), along with staff, key volunteers, and partners, delineated a five-year strategic plan for 2017 to 2021 (Hidden Harvest, 2018). Most notable are the ambitious goals for year 5 , including increasing annual funding to $>\$ 300,000$; growing harvesting and volunteer management to cover the whole city in response to increased demand to participate; automating harvest coordination with a reservation system; and achieving governance sustainability. ${ }^{5}$

\footnotetext{
${ }^{5}$ Future research could involve follow-up evaluation of the opportunities and constraints realized in executing this five-year plan.
} 


\section{Not Business-as-Usual: Transformative Potential Realized}

Because organizations like Hidden Harvest are not commonly considered in the social economy literature, a more nuanced conceptualization can help us better understand how urban gleaning projects challenge and redefine mainstream economic values. Gibson-Graham's (2006) work on diverse economies provides a nuanced framework as it incorporates notions of social economy into a larger and more complex context of multiple economic relations produced through diverse forms of social interaction. The following section situates Hidden Harvest as an illustrative example of Gibson-Graham's notions of community/alternative/ethical economy - as one initiative that destabilizes dominant economic assumptions. In fact, this case study raises profoundly political issues with transformative potential, such as reconceptualizing surplus, making visible myriad nonmonetary returns, bridging the gap between alternative and conventional economies, and normalizing access to public space.

\section{Reconceptualizing 'Surplus' and Thus 'Profit'}

Surplus, in economic terms, represents total revenue generated after accounting for the fixed and variable costs of production. ${ }^{6}$ While fixed costs for Hidden Harvest are limited, they include insurance, set-up costs such as incorporation and website hosting, and harvesting infrastructure and equipment (plus depreciation and replacement of such means of production), but currently not rent. As detailed above, the organization mitigated many of these costs by partnering with businesses supportive of their broader social and environmental mission. Variable or direct costs proportionate to output (harvests) are similarly limited: people get themselves to the harvest, so fuel costs are absorbed; the model relies on volunteer labor ${ }^{7}$ and one paid staff person, supported by government grants; and the raw materials are the rescued fruit and nuts. Regarding the latter, the costs of securing them involve the time and energy to document their existence and negotiate access, and allocation of one-quarter of the harvest to private landowners when desired (otherwise it is donated). At this point, there is limited competition for raw goods in this realm.

Hidden Harvest's model, wherein at least onequarter of all harvest is donated to those in need, reflects an ideological commitment to redistribute surplus in a fundamentally ethical and equitable way. This simple act normalizes for all involved a charitable aspect to self-provisioning and consumption. Imagine if every time an individual spent $\$ 100$ at the grocery store, a surcharge of $\$ 25-$ onequarter of the "harvest"-were added? In fact, food agencies use this tactic during annual food drives when they distribute donation bags at the start of a shop. Many of the folks attracted to these harvests embrace this community orientation readily, with some participants attending the harvests with the intention of donating their own share rather than retaining the food.

Hidden Harvest donates one-quarter of its raw material, and all of the corresponding embodied labor represented in its harvesting, out of an ideological commitment to more ethical sharing of bounty. The surplus that would typically remain in private hands as profit is voluntarily shared to benefit as many people as possible. As Gibson-Graham (2006) points out, many alternative community-based initiatives are about "resocializing economic relations" (p. 79), and the act of donating one-quarter of the surplus would be consistent with Gibson-Graham's characterization of commerce and sociality: "These practices involve ethical considerations and political decisions that constitute social and economic being" (Gibson-Graham, 2006, p. 83). It reflects a recognition of the embeddedness within community - conceived of primarily at the neighborhood scale — and the responsibility of enterprise to not only operate in a self-sustaining way, but also benefit those in need.

\footnotetext{
${ }^{6}$ Further regarding the notion of 'surplus': do the fruit and nut tree harvests represent previously untapped surplus? Or expropriated surplus from other species? Or a little bit of both?

${ }^{7}$ As Garlough notes, conventional u-pick farms leverage similar reductions in variable costs on transportation of finished product and 'volunteer' labor.
} 
Profit is broadly understood to represent a financial reward for the risks capitalists take in their entrepreneurial activities. But it remains an inherently problematic notion, since most social and environmental costs are externalized and thus not represented in market prices-generating an illusion of profit enacted in the economy in real and deleterious ways.

\section{Bridging the Gap between Alternative and Conventional Economies}

Hidden Harvest's aim to enhance local economies remains a long-term project, and its impacts are not easily measured through conventional conceptualizations of economic values. As a social enterprise, Hidden Harvest ultimately aims to become profitable. However, its approach to understanding profit differs from the narrow capitalist definition, which more often than not relies on the exploitation of 'other,' whether 'other' involves labor, species, generations, and/or natures. Instead, it views profit as a social good that ought to benefit the broader community. Co-founder Katrina Siks lamented the notion of profit as a less desirable goal for an organization than striving to create social good, and posited the idea that "good work should generate good pay," in that people who engage in work that benefits the wider community should be afforded a living wage.

As Hidden Harvest develops the capacity to generate funds independently, it seeks to build and strengthen partnerships with local businesses, particularly with food processors. Using the organization's quarter share of fruits retained during harvest events, Hidden Harvest approaches local food processors interested in using the harvested fruits in their products; to date the products include preserves and beer. These exchanges often involve bartering, and Hidden Harvest is able to monetize the transactions with food processors by taking a share of the profits of the final product. To build on these arrangements, Garlough hopes to enact a supply-management model in which Hidden Harvest could be guaranteed a more consistent and stable income. In this, 'sponsorships' would be sold to food processors and business, allowing them the first right of refusal to a specific type of fruit in a particular neighborhood, along with pictures and a social media story about the harvest events and trees to share with consumers. The proposed model would emulate a community supported agriculture (CSA) model by selling foods while sharing risks with buyers.

Since Hidden Harvest's activities function within a nontraditional economic model, it is difficult to estimate more concrete economic impacts. 'Profit' and other economic outputs are typically calculated in a monetary sense and may not be evident when working in alternative economies. While the organization is able to successfully conduct most of its activities outside the formal economy, it nevertheless needs to evaluate the monetary value of its activities to be able to communicate its impact to the government and other potential funders.. As such, it uses social returns on investment (SROI) as a tool to estimate how its activities generate direct economic benefits for the community. This tool provides a means to convey the monetary value of typically non-economic activities using proxies (Rotheroe \& Richards, 2007). These noneconomic activities include the ecological and social goods produced by harvest events, which make indirect, but nonetheless important, contributions to local economies. For instance, the organization attempts to recognize the multifaceted values of fruit trees in urban areas, which provide tangible goods, in the form of food, as well as essential ecosystem services.

Equally, Hidden Harvest seeks to acknowledge the role of harvest events and other activities in building social capital through experiential learning processes. In drawing from food sovereignty principles, the organization attempts to build capacity so that people are able to have control over their food system. These capacity-building efforts include the teaching of food skills through workshops on food preservation and preparation, as well as advocacy efforts that allow volunteers to gain experience in policy-making processes. While earning these tangible skills, volunteers gain an appreciation for how food is grown, and for those that grow it, through a more hands-on participation in their local food system.

Harvest events create spaces for diverse and underrepresented populations in the food system, including low-income populations, people with 
disabilities, women, New Canadians, ${ }^{8}$ and Indigenous people, ${ }^{9}$ to learn about and access fresh, healthful foods, and in certain cases, culturally significant foods. Members of the Hidden Harvest board and steering committee, like so many actors in the food movement, are predominantly from White, middle-class backgrounds. To break barriers, they have made a concerted effort to work directly with food agencies to secure multiyear grants to train, equip, and support Hidden Harvest's volunteer neighborhood leaders. To date, Hidden Harvest has worked with Parkdale Food Centre, Dalhousie Food Cupboard, Gloucester Emergency Food Cupboard, and Centre 507. However, in fairness, the success of this initiative has been mixed. While the diversity of volunteer harvesters has increased greatly (and now includes foodbank clients), the neighborhood leaders tend to be food bank volunteers. Foodbank clients who have expressed an interest in leading, for various reasons, have not managed to continue their leadership role for more than a year. Hidden Harvest further strives to break down barriers by donating culturally significant foods, such as elderberries, serviceberries, Concord grapes, black walnuts, and ginkgo nuts to many of the food banks noted above, as well as to the baby food cupboard run by Minwaashin Lodge (an Indigenous women's support center in Ottawa). Recipients have genuinely appreciated these foods, as they are rarely donated and are otherwise difficult to access.

In further developing social capital, the organization endeavors to build different social networks, and thus relationships around food, between and among food agency coordinators, local processors, business operators, harvest volunteers, and leaders. The networks and relationships are further strengthened through the local design of harvest events, in which the algorithm used for invitations is centered around specific geographies to facilitate participation and community cohesion. People are more likely to attend a harvest close to home, and in so doing, get to know their neighborhood as well as the trees and people in it.

\section{Challenging Blinders: Transformative Potential Unrealized}

Having summarized the transformative potential Hidden Harvest achieves, this section explores the broader significance of this type of initiative as a manifestation of community economy that ultimately spurs greater interconnection and reflects on its unrealized transformative potential, including the challenges it must overcome in this regard.

To begin, Gibson-Graham's (2006) notions of 'community economy' and 'ethical economy' offer a productive site of engagement. First, understanding urban gleaning, which is ostensibly autonomous collective self-provisioning, as an expression of community economy allows us to evaluate its more disruptive and potentially transformative potential to oppose dominant economic relations. The act is inherently communal-a physical coming together to harvest local landscapes. Construction of community is place-based, privileging localized relations as harvests are first broadcast within a given geographic area or neighborhood to recruit hyperlocal volunteers and then broadcast more broadly only when extra labor is required. For Gibson-Graham, community economy involves "a set of concepts and practices concerned with economic interdependence" (2006, p. 79).

Figure 1 delineates the ways Hidden Harvest corresponds closely with Gibson-Graham's characterization of community economy.

\section{Fostering Interconnection and Re-Embedding Identity in Place}

All of the 'community economy' attributes described above result in greater interconnectionwithin community, and between human and nonhuman species-across time and space. Urban gleaning initiatives connect people to one another, and to the place in which they live. They help connect the elderly, who may no longer be able to harvest their own trees, to those who can. They help connect people to their cultural roots, evoking memories for those transplanted from remote geographies and ecosystems. Founder Garlough

\footnotetext{
${ }^{8}$ The term "New Canadians" refers to newcomers to Canada, including recent immigrants and refugees.

${ }^{9}$ The extent of that diversity is impossible to estimate, as Hidden Harvest currently does not have the capacity to track the demographic data of their participants.
} 


\section{Figure 1. Ways Hidden Harvest Manifests Principles of Community/Alternative Economy}

\begin{tabular}{|c|c|}
\hline Aspect of Community Economy & Application to Hidden Harvest \\
\hline place-attached & privileges hyperlocal scale, neighborhood residents \\
\hline diversified and multiple & 184 trees or vines harvest in 2017 across 10 plant types and various species \\
\hline small scale & comprises $\sim 2-8$ volunteers per harvest \\
\hline cooperative & requires voluntary collaboration, unpaid labor, access to private property \\
\hline decentered & assigns decision-making to board and neighborhood leaders \\
\hline culturally distinctive & includes harvest of culturally significant plants \\
\hline socially embedded & situates food-bearing trees within neighborhood social relations \\
\hline dispersed & conducts harvests events and workshops across the city \\
\hline autonomous & $\begin{array}{l}\text { facilitates self-organizing harvests through technological platform and trained } \\
\text { neighborhood leaders }\end{array}$ \\
\hline oriented to local market & $\begin{array}{l}\text { works with local businesses such as Beau's and Michael's Dolce for value-added } \\
\text { processing }\end{array}$ \\
\hline values long-term investment & delineates ambitious long-term strategic plan \\
\hline vitality oriented & aims to foster food security and community vitality \\
\hline recirculates value locally & shares surplus for collective impact (intrinsic to model) \\
\hline community owned & no; for-profit social enterprise \\
\hline community led & relies on neighborhood leaders \\
\hline community controlled & steering committee provides governance \\
\hline $\begin{array}{l}\text { communal appropriation and } \\
\text { distribution of surplus }\end{array}$ & yes; modus operandi, raison d'être \\
\hline environmentally sustainable & fosters deeper connection to and protection of urban ecosystems \\
\hline ethical & yes; $1 / 4$ of raw materials donated to charity \\
\hline locally self-reliant & aims for independent income generation that is locally embedded \\
\hline
\end{tabular}

Source: Adapted from Figure 23, “Keywords of economy and community economy” in Postcapitalist Politics, Gibson-Graham (2006, p. 87).

recounted instances of harvest participants keen to access particular fruits and nuts that feature in their traditional cuisine that are not readily available in retail locations. He pointed to elderly participants eager to harvest black walnuts, as evocative of their childhood diets, as well as Asian immigrants keen to access ginkgo, which holds cultural significance for them. Community-based gleaning further connects people to place across time, and in so doing, to the survival strategies of our ancestors, who surely would have valued these trees for the food they provide. All these activities re-embed identity in place, and few such activities in our foodscape are so obviously performative in this sense: gleaning and foraging, ecological restoration, purchasing a CSA, gardening, and attending a farmers market all come to mind. As participants engage in intimate ways with their urban trees, they actively reembed identity in place-recognizing that identity and place help bring each other into existence.

Moreover, the practice can help connect lowincome and other marginalized populations to their local ecologies. To this end, Hidden Harvest collaborates with local food banks to train and equip neighborhood leaders based at those food agencies to run harvest events involving clients and community members. If turnout is low for a given event, the online system can suggest other volunteers to bolster capacity. Thus far, the organization has worked with Parkdale Food Centre and Dalhousie Food Cupboard (2014-2016, through grant funding from the Trillium Foundation), and Gloucester 
Emergency Food Cupboard (2017-2018), and Centre 507 (2018, through grant funding from the Ottawa Community Foundation).

Initiatives such as Hidden Harvest counter feelings of alienation and social isolation, allowing people to bind themselves in meaningful ways to each other, their home place, and urban ecosystem.

\section{Ensuring Financial Viability}

To ensure its long-term sustainability, as a forprofit enterprise, Hidden Harvest seeks to become a self-sustaining, economically viable business that does not rely on external or grant funding, distinguishing it from other similar urban gleaning and harvest organizations. Herein lie the limits to social enterprise: they can be as all-consuming as running a small business, with similar odds of success or failure, and business logistics can distract from the core mandate and broader pro-social and environmental mission. The pursuit of economic viability has led the social enterprise to form unique and meaningful partnerships with local food processors (Michael's Dolce, Beau's All Natural Brewery) and other businesses (Bridgehead Coffeehouse) in a move to secure a more stable form of income. Harvest events and outreach activities aim to enhance community food security and sovereignty, and local ecologies and economies. Although the organization still relies on grant funding to operate, its ability to innovate and develop networks has enabled it to grow and develop distinct ties and networks in Ottawa.

\section{Figure 2. City's Adopted Waste Hierarchy}

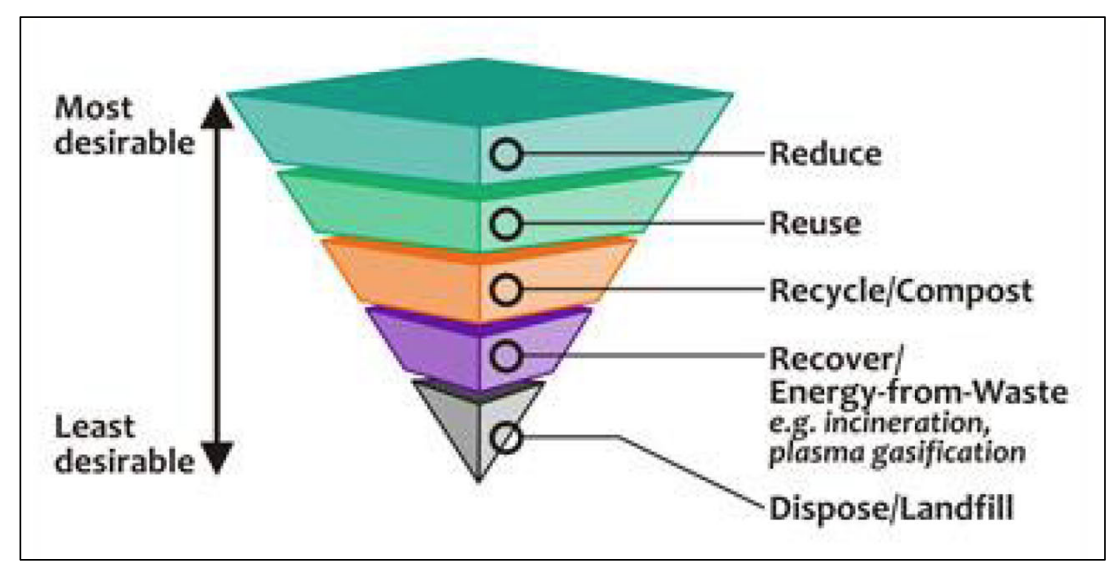

Source: City of Ottawa, 2012, p. 3.

\section{Resignifying the Economy Contingent on Municipalities Shifting Their Frame}

Garlough often quips that once you begin to look for fruit and nuts to rescue, "You start to see the world through 'fruit goggles' - wherein you start to see something everywhere" (Garlough, 2017). In fact, we must challenge our municipal officials and funders to put on SROI goggles when they consider the value of Hidden Harvest and similar civil society initiatives and social enterprises. In terms of the city's budget allocations, the work and potential of Hidden Harvest remain undervalued by municipal authorities, and thus under-resourced.

As a case in point, consider the ways in which cities think of and deal with trees, food, and waste. Notably, Ottawa posits the following schema as its adopted waste hierarchy (see Figure 2). However, the reality is that household waste in the city still largely ends up in landfills, rather than being diverted when possible. The city spends less on compost and recycling promotion and education compared with other large Ontario municipalities, and limits to the composting program mean that residents of multi-unit buildings and high-rises often cannot participate (CBC News, 2017).

At a City of Ottawa environment committee meeting on November 27, 2015, Garlough and cofounder Siks attempted to influence the draft 2016 municipal budget. Alluding to Figure 2, they asked the committee how much money would be spent on the supposedly "most desirable" outcomes of "Reduce" and "Reuse." The response was CA\$0"nothing." Meanwhile, Garlough lamented that the budget allocation for all other outcomes-composting, recycling, generating energy from waste, and disposing of waste in landfill_-were clearly delineated and generously supported, each with multimillion dollar budgets.

Hidden Harvest asserts a fundamental paradigm shift in how food waste ought to be treated, illustrated in Figure 3. They posit an approach to mitigating food waste aimed 
first at reducing, then feeding people in need, then feeding livestock, then composting and generating $100 \%$ renewable energy, and only then, if absolutely necessary, disposing of remaining material (Stuart, n.d.). However, before Hidden Harvest can secure municipal contracts for services or charge prices that adequately reflect the value (writ large) or collective impact generated, a fundamental resignification of the economy would be required.

\section{Conclusions}

Our study examines the for-profit social enterprise Hidden Harvest Ottawa, an urban fruit and nut gleaning initiative, in light of its transformative potential as an illustrative example of GibsonGraham's community economy. Hidden Harvest exemplifies Gibson-Graham's (2006) understanding of transformative potential as multiscalar and multifaceted, making use of existing and contextspecific materials and actions: “...we can start where we are with any site within a diverse economy and at any scale, from the local to the global, to begin to build community economies" (p. 167). Thus, grassroots action can be thought of as a starting point for socio-economic transformation.

First, in normalizing the charitable donation of one-quarter of its raw materials, and its embodied labor, and distributing equitably remaining surplus, the organization fundamentally reconceptualizes the profit typically held in private hands in more ethical and distributive terms, and in so doing, re-embeds the social in community-based economic relations (following Gibson-Graham, 2006). It begs the questions: How can we normalize mandatory public redistribution of surplus? As these initiatives seed locally, could they inspire others elsewhere?

Second, in myriad ways, Hidden Harvest augments meaningful connection: harvesters to each other, to landowners, to local food agencies, to place and nature. Urban gleaning can be a progressive practice for food self-provisioning, with the potential to engage diverse and marginalized communities.

Third, Hidden Harvest makes visible a SROI-in other words, a non-economic return; and it challenges traditional neoclassical economic assumptions, highlighting tensions between social economy and social entrepreneurship. These concepts are overlapping but not identical, and the latter is often posited as the desired strategy for nonprofit organizations to become financially viable. In fact, though on paper Hidden Harvest runs as a for-profit social enterprise, it shares many similarities with nonprofit and charitable civil society initiatives: from its explicit and expansive cultivation of community, remaining mindful to attempt to include marginalized communities; to its pursuit of grant funding to cover core operational costs (if they are covered at all); to its reliance on volunteer labor as a critical element of the means of production-one that covertly teaches consumers the value of production. To this end, the organization may become a project of Tides Canada, a move that would grant them charitable status and thus make them eligible to apply for grants to cover core annual funding and issue charitable tax receipts for personal donations.

Fourth, both social enterprises and nonprofit civil society organizations must make visible their extra economic social return on investment to 
warrant, in the case of the former, prices charged for goods, and in the case of the latter, grant funding. To this end, Hidden Harvest has developed an SROI tool to illustrate its larger collective impact, i.e., beyond the economic value of harvested fruits and nuts. Perhaps this tool could be of use to other similar initiatives.

Fifth, the following prescriptive recommendations primarily aimed at municipalities would help to advance urban gleaning initiatives:

- Support the planting of edible landscapes and encourage registration of existing edibles on public and private lands;

- Improve access to public space for food self-provisioning;

- Divert funding from less desirable forms of waste mitigation to models like Hidden Harvest;

- Reduce regulatory barriers to facilitate urban gleaning;

- Site urban green spaces adjacent to lowincome and food-insecure people;

- Conduct public awareness campaigns about what is safe and edible to harvest from urban environments, further elevating the profile of urban harvesting efforts;
- Involve diverse, underrepresented, and marginalized populations in gleaning activities; and

- Consult with immigrant populations and ethnic communities for culturally appropriate plantings.

However, Hidden Harvest's long-term success, and the success of similar initiatives in other cities, requires a reconceptualization of value by economic decision makers. Funders and municipal officials must sport SROI goggles, and allow what is made visible to influence their funding decisions, policies, and governance. To date, the state fails to adequately embrace the transformative potential of Hidden Harvest because it fails to value its collective impact. Only by expanding how profit is conceived and what 'counts' as economic, can the work that Hidden Harvest and similar organizations do be fully captured and appreciated.

\section{Acknowledgments}

The authors wish to thank Jay Garlough and Katrina Siks for the time and information they provided. Garlough, in particular, was an endless source of insights, feedback, and enthusiasm throughout this research.

\section{Web Resources:}

Falling Fruit: https:// fallingfruit.org

LifeCycles Project: http://lifecyclesproject.ca

Not Far From the Tree: https://notfarfromthetree.org

Iskashitaa Refugee Network: http://www.iskashitaa.org

Operation Fruit Rescue Edmonton: https://operationfruitrescue.org

Les Fruits Défendus: https://santropolroulant.org/en/what-is-the-roulant/collectives/fruits-defendus/

\section{References}

Anderson, J. (2004). Talking whilst walking: A geographical archaeology of knowledge. Area, 36(3), 254-261. https://doi.org/10.1111/j.0004-0894.2004.00222.x

Bartlett, B. (2012). Revealing the hidden harvest: Prospects and challenges for urban fruit tree projects. Vancouver Current Issues Paper, 1-44.

Bethea, C. (2018, April 23). The Robin Hoods of food waste. The New Yorker. Retrieved from https://www.newyorker.com/magazine/2018/04/30/the-robin-hoods-of-food-waste

Canadian CED Network. (n.d.). The social economy. Retrieved September 26, 2018, from https://ccednet-rcdec.ca/en/page/social-economy-0

CBC News. (2017). Ottawa lagging on waste diversion, group says. Retrieved from https://www.cbc.ca/news/canada/ottawa/ottawa-residents-among-province-s-worst-waste-diverters-1.4290259 
City of Ottawa. (2012). Ottawa's waste plan: Phase 2 - Discussion paper: Achieving our goals. Retrieved from http://ottawa.ca/calendar/ottawa/citycouncil/ec/2012/06-19/03\%20- $\% 2012$ jun $15 \% 20-\% 20$ Reference $\% 20$ Document $\% 5$ B $2 \% 5$ D.pdf

City of Ottawa. (2017). Putting down roots for the future: City of Ottawa urban forest management plan, 2018-2037. Retrieved from https://documents.ottawa.ca/sites/default/files/final ufmp en.pdf

Clark, K. H., \& Nicholas, K. A. (2013). Introducing urban food forestry: A multifunctional approach to increase food security and provide ecosystem services. Landscape Ecology, 28, 1649-1669. https://doi.org/10.1007/s10980-013-9903-z

Elwood, S., \& Martin, D. G. (2000). "Placing” interviews: Location and scales of power in qualitative research. Professional Geographer, 52(4), 649-657. https://doi.org/10.1111/0033-0124.00253 http://doi.org/10.1177/1049732303259804

Falling Fruit. (2018). Falling Fruit - Map the urban harvest! Retrieved July 2019 from https://fallingfruit.org

European Economic and Social Committee. (2017). Recent evolutions of social economy - Study. Retrieved September 26, 2018, from https://www.eesc.europa.eu/en/our-work/publications-other-work/publications/recent-evolutionssocial-economy-study

Garlough, J. (2017, October 17). Hidden Harvest Ottawa: Local food access and local food waste. Presentation to ENST 2001 (Sustainable Futures: Environmental Challenges and Solutions) class at Carleton University, Ottawa, ON. Slide presentation in the possession of the corresponding author.

Garlough, J. (2018, October 12). Hidden Harvest Ottawa: Money doesn't grow on trees, but food does. Presentation to ENST 2001 (Sustainable Futures: Environmental Challenges and Solutions) class at Carleton University, Ottawa, ON.

Gibson-Graham, J. K. (2006). A postcapitalist politics. Minneapolis: University of Minnesota Press.

Harvey, D. (2007). A brief history of neoliberalism. Oxford: Oxford University Press.

Hidden Harvest. (n.d.-a). About Hidden Harvest Ottawa. Retrieved December 2018 from http://ottawa.hiddenharvest.ca/about/

Hidden Harvest. (n.d.-b). Hidden Harvest Ottawa on Vimeo. Retrieved December 2018 from https://vimeo.com/hiddenharvest

Hidden Harvest. (2013a). Hinterland who's who: Urban harvesters. Retrieved from http:/ / ottawa.hiddenharvest.ca/events/my-giving-moment/

Hidden Harvest. (2018). Hidden Harvest Ottawa's 5 year strategic plan. Retrieved from http:/ / ottawa.hiddenharvest.ca/research-numbers/hidden-harvest-ottawas-5-year-strategic-plan/

International Panel of Experts on Sustainable Food Systems [IPES-Food](. (2016). From uniformity to diversity: A paradigm shift from industrial agriculture to diversified agroecological systems. Retrieved from http://www.ipes-food.org/ img/upload/files/UniformityToDiversity FULL.pdf

Johnson, S., \& Ballamingie, P. (2010). Social entrepreneurship. In N. Cohen (Ed.), Green business: An A-to-Z guide (Volume V, Article No. 129). Thousand Oaks, CA: SAGE. https://doi.org/10.4135/9781412973793.n129

Knezevic, I., Hunter, H., Watt, C., Williams, P., \& Anderson, B. (2014). Food insecurity and participation: A critical discourse analysis. Critical Discourse Studies, 11(2), 230-245. https://doi.org/10.1080/17405904.2013.866590

Marshman, J. (2015). Gleaning in the 21st Century: Urban food recovery and community food security in Ontario, Canada (Master's thesis). University of Waterloo. Retrieved from https://uwspace.uwaterloo.ca/bitstream/handle/10012/9736/Marshman Jennifer.pdf

McLain, R. J., Hurley, P. T., Emery, M. R., \& Poe, M. R. (2014). Gathering "wild” food in the city: Rethinking the role of foraging in urban ecosystem planning and management. Local Environment: The International Journal of Justice and Sustainability, 19(2), 220-240, https://doi.org/10.1080/13549839.2013.841659

McMurtry, J. J. (Ed.). (2008). Living economies: Perspectives on Canada's social economy. Toronto: Edmond Montgomery Publications.

Milanovic, B. (2016). Global inequality: A new approach for the age of globalization. Cambridge: Harvard University Press.

Monro, A. (2018, April 6). Hidden Harvest named best social enterprise at the Second Ottawa Social Impact Awards. Retrieved from https://apt613.ca/hidden-harvest-wins-in-social-enterprise-in-the-2nd-edition-of-the-ottawa-social-impact-awards/ 
Nordahl, D. (2014). Public produce: Cultivating our parks, plazas, and streets for healthier cities. Washington: Island Press.

Patel, R. (2007). Stuffed and starved: Markets, power and the bidden battle for the world's food system. Toronto: HarperCollins.

Perelman, M. (2003). The perverse economy: The impact of markets on people and the environment. New York: Palgrave Macmillan.

Poe, M. R., McLain, R. J., Emery, M., \& Hurley, P. T. (2013). Urban forest justice and the rights to wild foods, medicines, and materials in the city. Human Ecology, 41(3), 409-422. https://doi.org/10.1007/s10745-013-9572-1

Poitevin-DesRivières, C. (2018a). Hidden Harvest: A case study. Waterloo, ON: Nourishing Communities, Sustainable Local Food Systems Research Group. Retrieved from http://nourishingontario.ca/the-social-economy-of-food/casestudies-subversions-from-the-informal-and-social-economy/hidden-harvest/

Poitevin-DesRivières, C. (2018b). Field report: Uncovering bidden urban bounty: A case study of Hidden Harvest. Manuscript submitted for publication.

Responsible Investment Association. (2016). Canadian impact investment trends report. Toronto: Responsible Investment Association.

Rotheroe, N., \& Richards, A. (2007). Social return on investment and social enterprise: Transparent accountability for sustainable development. Social Enterprise Journal, 3(1), 31-48. https://doi.org/10.1108/17508610780000720

Sachdeva, S., Emery, M. R., \& Hurley, P. T. (2018). Depiction of wild food foraging practices in the media: Impact of the Great Recession. Society \& Natural Resources, 31(8), 977-993.

Stuart, T. (n.d.). Feeding the 5000: Food W aste Pyramid. Retrieved November 2018 from http://www.feeding5k.org/businesses + casestudies.php

Thompson, D. (2012). Weavers of Dreams: Founders of the Modern Cooperative Movement (2nd Ed.). Wausau, WI: Twin Pines Press.

Wakefield, S., Fleming, J., Klassen, C., \& Skinner, A. (2012). Sweet charity, revisited: Organizational responses to food insecurity in Hamilton and Toronto, Canada. Critical Social Policy, 33(3), 427-450.

https://doi.org/10.1177/0261018312458487 